\title{
EL JUEGO COMO
} VEHÍCULO DE SENSACIONES PLACENTERAS EN EL ADULTO MAYOR.

\section{GAMES AS A VEHICLE OF PLEASURABLE SENSATIONS IN ELDERLY PEOPLE.}

\section{O JOGO COMO VEÍCULO DE SENSAÇÕES PRAZEROSAS EM IDOSOS.}

Chiodi Susana ${ }^{1}$

Galizia Paola² Cravero Antonella ${ }^{3}$ Ormello Candela ${ }^{3}$ Pegoraro Magalí

${ }^{1}$ Licenciada en Psicomotricidad. Profesora de Promoción del desarrollo, Adolescencia, adultez y tercera edad Instituto Superior Ramón Menéndez Pidal de la ciudad de Río Cuarto. Autor responsable: Pje. El Chasque 1476. (5800) Río Cuarto Cel: 0358154842322 susana.chiodi@ yahoo.com

2Licenciada en Psicomotricidad. Profesora de Educación especial y trabajo Final. Instituto Superior Ramón Menéndez Pidal de la ciudad de Río Cuarto.

${ }^{3}$ Graduadas Psicomotricistas. Instituto Superior Ramón Menéndez Pidal de la ciudad de Río Cuarto

Trabajo recibido: 12 febrero de 2019. Aprobado: 02 abril de 2019.

\section{Proyecto de actividad de salud pública.}

\section{Resumen}

La OMS (Organización Mundial de la Salud) expresa que la esperanza de vida en personas mayores de 60 años está aumentando más rápidamente que cualquier otro grupo de edad en casi todos los países. Las políticas sobre el envejecimiento constituyen un desafío para la sociedad en su conjunto a fin de mejorar sus capacidades psicofuncionales. La psicomotricidad en la promoción de salud del adulto mayor, revaloriza el juego, como vehículo de sensaciones placenteras, la vivencia del movimiento y la relajación terapéutica, re significando las capacidades expresivo-comunicativas y práxicocognitivas. La modalidad taller vivencial corporal, llevada a cabo en el "Espacio Socio Cultural Arturo Ilia" de la ciudad de Río Cuarto (convenio con el Instituto Ramón Menéndez Pidal de la ciudad de Río Cuarto), contuvo a 20 adultos mayores entre 65 a 80 años cuyo análisis cualitativo-descriptivo permitió percibir el desenvolvimiento psicomotor de cada integrante, en su desafío de jugar.

Palabras clave: adulto mayor, salud, psicomotricidad, juego, cuerpo. 
The WHO (World Health Organization) states that life expectancy in people over 60 is growing faster than in any other age group in most countries. Policies regarding aging are a challenge for society as a whole, in order to improve psycho-functional skills. Psychomotor activity in the elderly health promotion adds value, as a vehicle of pleasurable sensations, experience of movement and therapeutic relaxation, giving a new meaning to expressive, communicative, practical and cognitive abilities. The experimental workshop, held at "Espacio Socio Cultural Arturo Illia" in the city of Rio Cuarto (agreement with the Institute Ramon Menendez Pidal from the city of Rio Cuarto), included 20 people between 65 and 80 years old; their qualitative and descriptive analysis reflected each participant's psychomotor performance when playing.

Key words: elderly, health, psychomotor activity, game, body.

\section{Resumo}

La OMS (Organização Mundial da Saúde) salienta que a expectativa de vida em pessoas com mais de 60 anos está aumentando mais rapidamente do que qualquer outro grupo etário em quase todos os países. Políticas de envelhecimento são um desafio para a sociedade como um todo, a fim de melhorar suas capacidades psicofuncionais. A psicomotricidade na promoção da saúde dos idosos, revaloriza o jogo como um veículo de sensações prazerosas, a vivência do movimento e o relaxamento terapêutico, ressignificando as capacidades expressivo-comunicativas e práxico-cognitivas. A modalidade de oficina vivencial corporal, realizada no "Espacio Socio Cultural Arturo Ilia" da cidade de Río Cuarto (acordo com o Instituto Ramón Menéndez Pidal da cidade de Rio Cuarto), conteve 20 adultos com idade entre 65 e 80 anos cuja análise qualitativa-descritiva permitiu perceber o desenvolvimento psicomotor de cada participante, em seu desafio de brincar.

Palavras-chave: idoso, saúde, psicomotricidade, jogo, corpo.

\section{Introducción}

El presente trabajo de intervención psicomotriz, surge en el campo de la práctica educativoterapéutica en el adulto mayor.

En la actualidad se presenta la psicomotricidad como una "disciplina producto de la cultura, a la cual le interesan el cuerpo del sujeto y sus perturbaciones; tomando como objeto particular de estudio el cuerpo y sus manifestaciones refiriendo con ello a la actitud postural, la gestualidad y las praxias"(1)

La psicomotricidad se comprende entonces como una manera de concebir a la persona, de entender estas manifestaciones en tanto expresividad particular de un cuerpo global en el que confluyen aspectos motores, cognitivos y socio-afectivos como elementos que configuran la personalidad.

Resulta importante destacar que nuestro cuerpo es la herramienta fundamental desde donde poder mirar y escuchar, entrar o salir, pensar y transformar.

La inserción y formación de recursos humanos en la atención de la salud, requiere la capacidad perceptiva de interrogarse, sobre el funcionamiento del cuerpo no solo en lo biológico sino en su posibilidad de expresión sensible, subjetiva y discursiva.

Pensar lo Psicomotor, en el adulto mayor, supone comprender el cuerpo en calidad de receptáculo, en tanto el cuerpo recibe, acoge y lleva las huellas de su propia historia.

La praxis psicomotriz, requiere observar, analizar, diagnosticar en el campo de la organización tónica, la postura y el movimiento. Uno de sus modos y recursos instrumentales, es el juego y el jugar, en la vivencia lúdica. Las relaciones entre lo psicomotor, la cultura 
y los procesos de la corporeidad en el envejecimiento, delimitan un espacio de trama interdisciplinar, donde la recreación y re significación de las representaciones del mundo del adulto mayor, re-cobren o devuelven un sentido de vivir positivo en el placer de jugar, en un dispositivo preventivo que retoma el trabajo con el cuerpo físico, la sabiduría, y la incertidumbre de las condiciones de la vejez: “...porque llega mejor parado a la vejez, quien es capaz de enfrentarse a su propia inconsistencia, quién es capaz de soportar la incertidumbre de vivir, quién tuvo recursos para encontrar salidas creativas frente al desamparo que a todos de una u otra manera nos atraviesa". (2)

En este sentido, los contenidos, las actividades y la metodología, se dirigen al análisis cualitativo-descriptivo de las manifestaciones psicomotrices de un grupo de adultos mayores, que asisten a un centro integral cultural de la ciudad de Río Cuarto. Su enfoque reflexivo y técnico tiene como objetivo central el enriquecimiento de la formación profesional de la salud y la educación, de quienes acompañan y asisten a esta etapa del ciclo de la vida.

\section{Desarrollo}

\section{El cuerpo del adulto mayor: visión multidimensional}

Desde la psicomotricidad nos ocupamos del cuerpo y sus producciones, entendiendo que el cuerpo es protagonista y producto de la historia relacional del sujeto. El cuerpo es un tiempo y un espacio, no hay tiempo ni espacio, si no hay un cuerpo que lo habite, que lo transcurra.

Según Salvarezza, (3) el principal escenario donde se desenvuelve el drama de la vejez es el cuerpo y no es igual para todos los sujetos ni todos ellos recurrirán al cuerpo de la misma manera.

Podemos encontrarnos con cuerpos cuyas funciones están deterioradas y esto no los inhabilita para acceder a un adecuado funcionamiento y realización, o en su proceso inverso, podemos encontrarnos con adultos mayores sin alteraciones en sus funciones orgánicas pero que no logran ponerlas en funcionamiento.

En los adultos mayores es posible pensar en un cuerpo sano aun con un organismo deteriorado o enfermo, está relacionado con el habilitar ese cuerpo a partir de las posibilidades de ese organismo.

Habitar el cuerpo, es habilitarnos con nuestros deseos en un tiempo y un espacio, experimentar y darnos la posibilidad de realizar una pausa, construyendo una espera. No se trata de responder al ritmo que nos impone el afuera sino de escuchar el ritmo que viene de nuestro interior.

Habitar el cuerpo en la vejez implica asumir los cambios que van aconteciendo en él. Significa reacomodar la imagen del cuerpo al nuevo esquema corporal, un esquema al que hay que reconocerle nuevos ritmos en el sueño, y la alimentación, tendiente al aumento tónico, la rigidez, la lenificación de los movimientos y disminución de las funciones.

El proceso de envejecimiento es un proceso normal, biológico que implica la alteración gradual de la estructura corporal, de las funciones corporales y de la tolerancia al estrés impuesto por el ambiente.

Van surgiendo transformaciones que afectan espacialmente a la apariencia, como por ejemplo, la reducción gradual de la densidad ósea, la masa muscular y la fuerza muscular, como el declive de funciones sensitivas y el rango de movimiento. Pero también se suceden cambios internos no tan visibles como, pensamientos, dolores e imágenes que dan cuenta de las vivencias internas frente al hecho irremediable de envejecer.

La observación psicomotriz, según Papandrea (4) en su descripción del abordaje psicomotor del adulto, los signos psicomotores que se presentan con frecuencia en el cuerpo del adulto mayor son: 
$\checkmark \quad$ Alteraciones en el espacio, en el tiempo, en el ritmo, en la diferenciación del espacio propio y del otro.

$\checkmark \quad$ Alteraciones en el tono muscular y la postura, dificultad para mantener una posición, actitudes y posturas muy rígidas o muy blandas.

$\checkmark \quad$ Desajustes en la imagen del cuerpo, modos de pensarse a sí mismo desfasados de la apariencia o de la potencialidad del propio cuerpo.

$\checkmark \quad$ Alteraciones tónico emocional y afectivo, tendencia a la baja autoestima, actitud de omnipotencia o impotencia, exceso de exigencia, labilidad emocional, baja tolerancia a la frustración, reacciones emocionales desbordadas.

$\checkmark \quad$ Signos de digrafía y de torpeza psicomotriz.

$\checkmark \quad$ Funcionamiento inestable psicomotor o inhibido psicomotriz, manifestaciones de ansiedad explosiva o retenida, híper o hipo quinesia, dispersión de la atención, inquietud.

$\checkmark \quad$ Cambio en el ritmo de las coordinaciones dinámicas generales (mayor lentitud, mayor tiempo de espera, mayor duración en las secuencias de movimiento).

Es frecuente encontrar en los desarrollos teóricos relacionados al envejecimiento del cuerpo del adulto mayor y sus trasformaciones, un abordaje asociado casi exclusivamente a la perdida de funciones y al deterioro propio del envejecimiento biológico.

A consecuencia de esto se produce una igualación de los términos cuerpo y organismo, lo que genera una visión reduccionista del cuerpo, limitándolo solo a sus manifestaciones biológicas.

Consideramos necesario atender al organismo y atender al cuerpo. Y cuando decimos cuerpo estamos interesándonos por las interrelaciones subjetivas y socioculturales que se entraman en el hacer, sentir y pensar del sujeto adulto, en sus modos de ser y de estar. La práctica psicomotriz, pretende abordar, en todos los niveles de atención de la salud, una visión multidimensional de la concepción de cuerpo, que tenga en cuenta las connotaciones sociales como medio de entrada en comunicación con los otros y lugar de encuentro con uno mismo.

Las formas de envejecer, como señala Zarebski (5) es particular de cada sociedad en la que se vive. De allí que y propone analizar el proceso y el modo en el que el sujeto se posiciona frente a sí mismo. Tal posicionamiento, condicionará la calidad del armado de su curso vital.

Los estados de fortaleza o debilidad emocional dejaran ver la particularidad de la vejez en el ser humano: la discordancia entre lo que se siente, lo que se aparenta y lo que se es. Cada uno resolverá de modo particular entre el verse, el sentirse, el escucharse, y lo que se recibe de la mirada, la escucha, y el sentimiento de los otros.

Mediante la construcción de un yo complejo a lo largo del ciclo vital, el sujeto podrá sobrellevar la discordancia entre como se sabe y como se siente, reconocerse viejo a la vez que se siente joven, ya que adaptarse al paso del tiempo no significa resignarse.

Por un lado, tenemos aquellos adultos que tienen un concepto de vejez como sinónimo de enfermedad. Así es como se producen las depresiones, la disposición a toda clase de enfermedades orgánicas, que puede llegar hasta la demencia senil.

La posibilidad de reflexionar sobre el propio proceso de envejecimiento, significa, no la ausencia de enfermedad, sino saber cómo sobrellevar la patología, es decir, cómo los factores actitudinales y la capacidad de resiliencia inciden en los procesos subjetivos y en el modo de proceder frente a sí mismo y en relación a su contexto.

Un envejecimiento saludable, a lo que la autora denomina como "un viejo joven" desde una visión compleja del proceso de envejecimiento, es el hecho de tener un proyecto, permitirse desear, tener sueños, luchar para alcanzarlos, suficiente para mantenerse vital y lúcido, aunque haya que lentificar el paso, adecuar ritmos, y modificar hábitos:

"Mediante la construcción de un yo complejo a lo largo del curso vital, el sujeto podrá 
sobrellevar la discordancia entre cómo se sabe y cómo se siente, reconocerse viejo a la vez que se siente joven, ya que adaptarse al paso del tiempo no implica resignarse". (6)

De esta manera, un indicio de un envejecimiento normal es cuando la persona reconoce y acepta su condición envejecida, incorporando las marcas biológicas y sociales de su envejecimiento, en una actitud de autoestima positiva que muestra el reconocimiento de sus estados de angustia, pero cuenta con recursos para superarlos.

Los espacios reflexivos y de prácticas que aportan al proceso adulto, desde disciplinas como la Psicogerontología y la Psicomotricidad, coinciden en la toma de conciencia hacia la recuperación, prevención, y asistencia en el abordaje de propuestas futuras integrales y multidimensionales, en la mirada compleja de los adultos mayores. Nuestra disciplina pone de relieve la construcción de la corporeidad en relación con otro y es en esa trama vincular que el cuerpo se manifiesta en sus dimensiones tónico emocional, práxicocognitivas e instrumentales.

\section{¿Por qué un taller vivencial?}

La presente experiencia planteó un trabajo grupal, en equipo, donde se pone al cuerpo en juego, entre los participantes adultos mayores y los estudiantes. Punto de encuentro para trabajar, experiencias personales, de intercambios, conocimientos en común, afectos y experiencias cotidianas.

Se llevó a cabo en una secuencia de 10 talleres vivenciales, con una duración de 1 hora cada uno, según lo previamente establecido con la institución, aplicados una vez por semana durante los meses de agosto/ noviembre de 2018.

La hipótesis que guio el trabajo es el juego como herramienta de intervención de la psicomotricidad, reactiva la sensorialidad y el placer del movimiento, en los procesos psicobiológicos del cuerpo del adulto mayor.

En función del juego como estrategia de intervención se propusieron como objetivo general: Promover el juego como vehículo de sensaciones placenteras en el cuerpo del adulto mayor y como específicos:

$\checkmark \quad$ Reencontrar las capacidades expresivas del cuerpo, verbales, corporales y grafo plásticas.

$\checkmark \quad$ Vivenciar el tono muscular en sus estados de tensión y distención.

$\checkmark \quad$ Posibilitar la experiencia de la relajación.

$\checkmark \quad$ Experimentar el placer por el movimiento a través de estímulos sonoros, visuales, musicales.

$\checkmark \quad$ Potenciar el encuentro con el otro a través de situaciones lúdicas.

El trabajo corporal liga limitaciones y posibilidades psicomotoras, articulando la vivencia sensoperceptiva al plano simbólico del lenguaje y la representación.

Los talleres vivenciales actúan como lugar de placer sensorial y motriz, de percepción y reacción, de acercamiento al cuerpo propio y al cuerpo del otro.

Las sesiones de psicomotricidad, en esta modalidad, fueron organizadas en cinco tiempos:

1. La bienvenida, la presentación, el reencuentro (el nombre, evocación de la sesión anterior). Se construye la continuidad de la experiencia.

2. Trabajo sobre el tono (la respiración, estiramientos y movilización). Es la primera toma de conciencia sobre el cuerpo. Conectar con las sensaciones internas y posibilidades de movilización corporal. Es desbloquear las tensiones corporales y malestar progresivamente acumulados.

3. El juego y la relación con los objetos: telas, globos, pelotas, bastones, música. Movilizar el despertar sensorial y motriz; la disposición a los cambios, el acceso a 
imaginar, desear y fantasear.

4. Reapropiación y conciencia (a través de propuestas como la relajación y el masaje al otro). Propuestas cautelosas y progresivas, porque para muchos el contacto con el otro es algo lejano. Recurso no solo para ablandar o calmar al cuerpo brindando la posibilidad al adulto mayor de estar a "la escucha de lo que sucede en su cuerpo".

5. Despedida, cierre. Cada integrante expresa su sentir, sobre la sesión, la palabra ocupo un lugar central. Se utilizó como medio de expresión, la plástica, para explorar los modos de dibujar, plegar, recortar, pintar, pegar, en un proceso de transferencia gráfica para leer el cuerpo en una escritura lúdico-creativo.

\section{¿Por qué los adultos necesitan jugar?}

Cuando se utiliza el juego en la práctica psicomotora, lo hacemos pensando en propiciar a los adultos mayores una experiencia placentera que les brinde alegría, mejore su autoestima, y conocimiento de sí mismo, facilitar sus relaciones interpersonales. Desarrolle la creatividad, mejore las relaciones interpersonales, la capacidad de comunicación y reducción de la ansiedad- estrés- sedentarismo y tensiones acumuladas.

En la práctica psicomotriz utilizamos el jugar para analizar, investigar, detenerse y practicar los modos del Psicomotricista para entrar y acompañar al adulto en ese espacio intermediario entre la realidad y la fantasía. Estar dispuesta a esa construcción conjunta, ayuda y acompaña la posibilidad del despliegue del cuerpo, gestiona nuevos modos de sentirse, pensarse, nombrarse y habitarse.

No se pretende trabajar con un cuerpo al que hay que ejercitar, mirando un cuerpocosa, cuerpo-objeto o cualquier otra imagen que fragmente el cuerpo. Sino trabajar con propuestas lúdicas que hagan su aporte a la construcción subjetiva del adulto mayor y lo habiliten a recorrer nuevos caminos para el reencuentro con su cuerpo actual.

La importancia de trabajar desde lo lúdico en la actualidad, con el adulto, implica transformar lo que está desvalorizado, marginado y desautorizado en la conciencia del adulto y dar paso al ejercicio del placer, la libertad, la imaginación, y es esto lo que nos proponemos abordar.

Desde la perspectiva de diversos autores, el juego es considerado una herramienta indispensable para nuestra disciplina, por ejemplo Cañeque (7) cita a Huizinga quién define "el juego es una acción o una actividad voluntaria, realizada en ciertos límites fijos de tiempo y lugar, según una regla libremente consentida pero absolutamente imperiosa, provista de un fin en sí, acompañada de una sensación de tensión y de júbilo y de la conciencia de ser de otro modo que en la vida real". Esta autora también cita a Caillois "La función propia del juego es el juego mismo. Ocurre que las aptitudes que ejercita son las mismas que sirven para el estudio y para las actividades serias del adulto (...). Es una característica del juego el no crear ninguna riqueza, ninguna obra. Al final de la partida todo puede y debe quedar igual que como estaba, sin que haya surgido nada nuevo". Por otro lado Cañeque op. cit. sostiene las siguientes caracterizaciones acerca del juego:

$\checkmark \quad$ La realidad en que se desarrolla dicho proceso es ficticia, en el sentido de que se estructura mediante una combinación de datos reales y datos fantaseados.

$\checkmark \quad$ Es improductivo, en el sentido que no produce ni bienes ni servicios.

$\checkmark \quad$ Es reglamentado, conforme va transcurriendo, estableciéndose reglas en el aquí y el ahora, en forma deliberada y rigurosamente aceptadas.

$\checkmark \quad$ Produce placer, es decir que la actividad en sí promueve en forma permanente un desafío hacia la diversión.

$\checkmark \quad$ El juego es una forma de intentar equilibrar el principio del placer y el principio de realidad.

Visto de esta manera, se genera un campo auto regulable, dentro del cual los jugadores 
determinan en forma libre y espontánea los momentos de excitación y tensión, tanto como los de calma, ensimismamiento y relajación.

En el juego, tanto adulto como niño pueden crear y usar toda su personalidad, descubriendo en esta instancia su propia persona.

Como se mencionó al principio de este trabajo, el campo de la Psicomotricidad se ha ido ampliando en sus intervenciones en las distintas etapas del desarrollo, lo que obliga a realizar una adecuación de recursos y técnicas, así como un estado de permeabilidad a la convivencia con otros saberes del cuerpo y del sujeto, frente a esto Papandrea (8) propone ampliar los recursos sin perder la especificidad, aportes de técnicas del trabajo corporal o técnicas corporales.

"Las técnicas remiten a la práctica, a los modos de abordaje, a los recursos o herramientas con que cuenta el Psicomotricista para entrar en trabajo, primero con su propio cuerpo y luego con el cuerpo del otro. Por eso las técnicas corporales son un medio y no un fin en sí mismas, aplicándose como medio para mirar, percibir y escuchar al cuerpo.” (8). Se ubica entonces al juego como herramienta para el abordaje terapéutico.

Marazzi (9) propone que en la práctica profesional hace falta adentrarnos especialmente en nuestro propio jugar con otros, registrar, analizar, hacer una lectura del jugar propio con otros y del jugar de los otros, del propio cuerpo en el jugar y del cuerpo de los otros. "Prestar atención al cuerpo en juego, en el espacio, en el tiempo, con los objetos, con los otros. Observando detalles de la entrada, de la permanencia, la salida del jugar, la posibilidad de jugar o la dificultad".

\section{Consideraciones Finales}

Al hablar del lugar del juego como expresión de sensaciones placenteras en la vida adulta, consideramos, por su enfoque y su contenido, la necesidad de profundizar teórica y técnicamente la formación corporal de los especialistas que trabajan con el cuerpo y que, necesariamente nos lleva a entrar en un proceso complejo que dependerá de la escuela de pensamiento, la disciplina y el cuerpo propio y el de los otros o de quien se trate.

Las diferentes disciplinas que abordan el cuerpo, debieran tener en cuenta que cada persona es única y diferente, que tiene necesidades y posibilidades diferentes, respetando lo que cada sujeto es, lo que puede, sabe y quiere.

La creación de un lugar de expresión corporal en el Espacio Socio Cultural Arturo Ilia, en el campo de intervención y exploración psicomotríz en el adulto mayor, radica, su importancia en dilucidar y pensar desde nuestro especificidad, cómo siente y habita su cuerpo, cómo percibe las sensaciones que emanan de su cuerpo, que no solamente aportan malestar o impedimentos, sino que también son una vía de disfrute y posibilidades. Ejemplo de ello, son algunos testimonios recogidos: "yo no sé dibujar", "como los niños de jardín”, "lo único que se dibujar es una casa”, “qué puedo dibujar?”... "Bueno, yo quiero saber cómo es esto, ¿lo voy a poder hacer?,". "Bueno; no sé bien; a ver si me sale"... "vos te crees que no me da vergüenza estar en la silla, pero si me llego a acostar no me puedo levantar"... "Nos gustó la actividad, la relajación”, "jugamos", "es como un mimo, porque por un momento nos olvidamos de lo que nos sucede", "si fuera por nosotras seguimos”... "me hace mal estar descalza”. "¿Eso es para llevar en la boca?” “¡Por qué a mí no me gusta!”... El cuerpo toma la palabra, a partir de las sensaciones agradables y desagradables que expresa el pensamiento.

La vejez implica cambios biológicos, conductuales y sociales. En general en el adulto mayor, se produce la disminución del movimiento y la preferencia por actividades pasivas, las cuales implican un despliegue corporal, donde el cuerpo se haya menor involucrado. La vivencia permite revalorizar el juego, como medio de sensaciones placenteras, aportando beneficios como ser: aumentar la autoestima, la capacidad creativa, el disfrute por el hacer, el placer, el reír, el compartir, el hacer con el otro, el hacer contra otro con 
fines lúdicos, el despojarse de las estructuras y reglas propias; despojarse del prejuicio de que el juego pertenece a la infancia, para empezar a mirarlo como actividad fundamental para el bienestar en la etapa adulta.

Fue progresiva la adaptación a esta dinámica lúdica, tras crear un vínculo de contención y acompañamiento, de escucha y de una mirada que sostiene y no juzga, poniendo en juego nuestro rol como psicomotricista el estar disponibles a la demanda del otro.

Proporcionar confianza, respetar sus tiempos, sus ritmos, su desenvolvimiento tónicoemocional, lo que verbaliza y lo que no. Estar disponibles es estar dispuestos tanto para dar como para recibir en este proceso continuo de intercambio e interacción con los adultos.

La importancia y necesidad de crear este servicio de salud recreativo e integral para el adulto mayor y de diálogo intergeneracional, se hizo posible gracias a la predisposición del establecimiento y a sus participantes.

El análisis de la corporeidad, en los adultos mayores, implica sumergirse en un territorio interdisciplinario que interrogue el lugar del cuerpo en los procesos subjetivos, biológicos y culturales de la tercera edad.

Jugar, es la capacidad de sentir y romper un orden establecido que permite dejar un espacio para la nuevo, la novedad, la incertidumbre, la creatividad.

Brindar un espacio lúdico de contención como dispositivo para hacer y sentir, cuyo límite es la producción de lo nuevo, la autoafirmación como sujeto adulto, es la tarea que deberemos seguir profundizando a fin de mejorar la calidad de vida del adulto mayor. Las vías de acceso que posibiliten al cuerpo del adulto poder expresarse, son un desafío para instituciones y futuros profesionales que se interesen por la prevención y promoción de su salud.

\section{Referencias Bibliográficas}

1. Calmels, D. Cuerpo y saber. Ed. D y B editores, Buenos Aires, Argentina. 2005, p15

2. Zarebski, G. Hacia un buen envejecer. Bs. As. Ed. Univ. Maimónides. 1999, p39-40

3. Salvarezza, L. Psicogeriatría. Teoría y Clínica. Ed. Paidós. Bs As. 1988.

4. Papandrea, A. El abordaje psicomotor de adultos. Ed. Imago Mundi. Argentina. 2018

5. Zarebski, G. Una vejez normal: hacia un buen envejecer. Ed. Univ. Maimónides. Bs.As. 1999

6. Zarebski, G. La teoría del curso de la vida y la Psicogerontología actual. La vejez en el curso de la vida. Encuentro Grupo Editor. Córdoba. 2011, p27

7. Cañeque, H. Juego y vida: La conducta lúdica en el niño y el adulto. Ed. El Ateneo. Bs.As. 1991.

8. Papandrea, A. Abordaje Psicomotor de adultos. Ed. Imago Mundi. Bs. As. 2018, p13

9. Marazzi, M. Acerca de las técnicas en psicomotricidad y en la formación corporal del Psicomotricista. Artículo de la Cátedra de Formación Personal Corporal II Y III de la Lic. En Psicomotricidad UNTREF. 2004, p7 